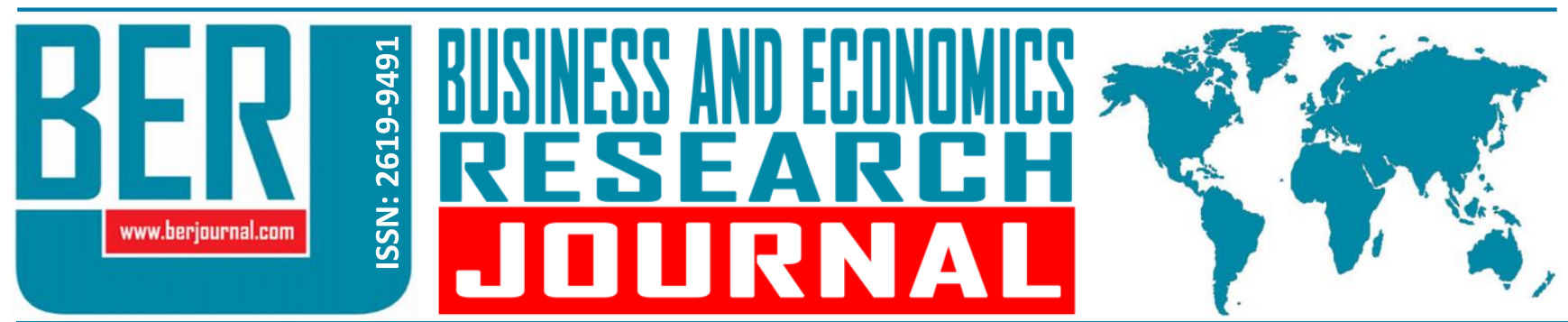

Business and Economics Research Journal Vol. 9, No. 4, 2018, pp. 773-785 doi: 10.20409/berj.2018.138

\title{
Oil Production as a Leading Indicator for Tanker Freight Market
}

\begin{abstract}
Abdullah Acik ${ }^{\mathrm{a}}$, Sadık Ozlen Baser ${ }^{\mathrm{b}}$
Abstract: The aim of this study is to determine the causality between oil production and freight rates in the seaborne oil transportation in the world. The causality with oil prices has been studied more in the literature, but the studies that examine the causality with oil production have been limited. However, the effect of the crude oil production amount on the market is also great. The methods that can detect delayed causality have been utilized unlike the existing literature. While the Baltic Dirty Tanker Index (BDTI) and Baltic Clean Tanker Index (BCTI) variables are used as the measurement for the tanker freight rates, the Bloomberg oil production index variable is used as the production measurement. The data set used in the study consists of 239 monthly observations covering between August 1998 and June 2018. Standard causality analysis developed by Granger (1969) is used for linear causality, and nonparametric tests developed by Hiemstra and Jones (1996) and Diks and Panchenko (2006) are used for nonlinear causality analysis. While linear causality cannot be spotted in the obtained results, nonlinear causality is determined. As a result of the four lagged nonlinear causality analyzes made, the causality is found from the second to the fourth lag for BDTI and from the first to the fourth lag for BCTI. According to these results, while the effect of changes in production is directly reflected in the product tanker market, it is reflected on the dirty tanker market with a delay. It is hoped that these results may be beneficial to developing business strategies and reducing risks for shipowners and charterers in the tanker market.
\end{abstract}

Keywords: Oil Production, Tanker Freight Market, Nonlinear Causality

JEL: C10, N70, R40
Received : 03 September 2018

Revised : 03 October 2018

Accepted : 10 October 2018

Type : Research

\section{Introduction}

It goes without saying that the recent decades have been a period of globalization of trade, capital flow and investments, which has led to imbalances between geographical regions and countries (Naccache, 2011). This imbalance necessitated transportation of raw materials to certain regions with advantages in production factors and distribution of final products to the markets. Most of these raw materials consist of fossil fuels that exert their superiority as major energy sources in the world. Dependence on fossil fuels in the world is still ongoing and does not seem to be ending soon despite technological advances. These resources have been haphazardly distributed around the world, and a great deal of their inter-country trade is carried out by sea. One of the most requested of these sources is crude oil, which constitutes about $18 \%$

a Res. Asst., Dokuz Eylul University, Maritime Faculty, Department of Maritime Business Administration, İzmir, Turkiye abdullah.acik@deu.edu.tr (ORCID ID: 0000-0003-4542-9831)

b Assoc. Prof., Dokuz Eylul University, Maritime Faculty, Department of Maritime Business Administration, İzmir, Turkiye, ozlen.baser@deu.edu.tr (ORCID ID: 0000-0001-6632-2617) 
of the tonnage of the transport made in 2016 (UNCTAD, 2018). Also it is widely considered to be one of the most important commodities affecting the global economic growth (Miao et al., 2017).

The value of a commodity usually differs from region to region. Contrary to this, theoretically the difference in the value of that commodity should be equal to the cost of transportation between the regions. Albeit, regional prices often differentiate by more than transport costs due to variations in regional supply and demand frameworks, seasonality, and the availability of transport opportunities (Alizadeh \& Nomikos, 2004). But the structure of oil price is more complicated than the other commodities.

The structure of the oil price is defined by Hamilton (2009) as changes in the real price of it have historically tended to be permanent, difficult to predict, and controlled by various regimes at different points in time. This situation causes too much surprises in oil price developments (Wirl, 2008). The factors affecting the price of oil have been examined by many researchers and their results are often intersecting. According to Miao et al. (2017), the prices are affected by dynamic and multi-dimensional factors which are listed as trading factors, financial market factors and physical market factors, and their predictions are quite difficult. The author also points out that situations that prevent very accurate foresights in prices are generally unexpected events such as demand shifts, supply disruptions, changes in oil production and inventory demand, and geopolitical events. Angelier (1991), another researcher, has divided the factors that simultaneously affect the price of oil into three which are also described as short term and long term. The balance between supply and demand is in the short term, and structure of the oil industry and the marginal production cost which is consistent with world oil demand are in the long term. The effect of the marginal cost referred by the author is also very important since even a country with the highest reserves of the world such as Venezuela cannot economically benefit from its resources at low oil prices because of the high cost of extraction. This situation lowers the motivation for exporting oil at low prices, however the increasing export at high prices causes supply surplus and puts downward pressure on oil prices. Some other researchers have identified factors that affect oil prices as supply-side and demand-side, while others have not. Poulakidas and Joutz (2009) have pointed out that supply-induced shocks in oil-exporting countries such as Russia and OPEC greatly increase volatility in oil prices. This situation is caused by the fact that oil consumption is global while oil production is being controlled by a limited number of oil-producing areas. However, in some cases increasing the supply may not be effective at prices. For example, OPEC agreed to reduce oil prices by increasing production in 2007 but failed to achieve this with the increase in demand from developing countries (Shi et al., 2013). Non-supply-side factors that may affect oil prices have been mentioned by Shi et al. (2013), and they are wars, dollar depreciation, increase in demand for oil caused by economic improvement, consumer confidence and tastes, and oil derivative markets. That is, demand-side changes are also very influential on oil prices. The practical factors that have caused oil prices to increase over the last decades have been investigated by Naccache (2011) and following statements have presented for the supply side; (i) low investment in the oil industry; (ii) scarcity of the resources; (iii) geopolitical instability in oil producing countries; (iv) the rice of the costs of many production factors; (v) production cut decisions of OPEC countries; (vi) information about low US oil stocks; and (vii) some extreme climate events which damage oil facilities. Price increasing factors on the demand side are the rise in oil demand especially stemming from China, India and other developing countries, and consistent energy demand from developed countries. Also market fundamentals and speculative pressures are effective in rising or crashing oil prices (Tokic, 2015). The studies conducted about which side is more effective on oil prices include different point of views. Naccache (2011) has argued that changes in oil prices are demand-driven rather than supply-driven. According to the research done by Archanskaıa et al. (2012), this situation changes over time. The main driver force behind oil price shocks was supply-driven between 1970 and 1992, but it changed to demand-driven between 1992 and 2006.

Unlike all these statements, it should also be stated that the final end use price depends on production costs, refining costs, marketing costs, and transportation costs of crude oil from exporting countries to consumer countries (Poulakidas \& Joutz, 2009). Within these costs, transportation factor, which is the focus of our study, also plays a very important role since reduction in this cost can provide a competitive market environment even with remote markets. 
There are no countries that do not use oil and the global effect of prices is certain. These effects can be examined by separating them as export-import effects and macroeconomic effects. Import-export is also a part of the macroeconomics, but it has been useful to make such a distinction to make sense easier. In this context, for oil importing countries, increase in oil price deteriorates the trade balance and makes current account deficit higher. For oil exporting countries, increase in oil price leads large trade surplus and high level of savings (Kilian et al., 2009). For instance, the oil prices per barrel reached \$145 in 2008 afterwards it started to drop sharply. The decline process continued at a rapid pace and oil price went down to $\$ 29$ per barrel. This situation resulted in a great decrease in the revenues of the oil exporting countries such as Russia and Saudi Arabia, generating stress on the economies, while in the net oil importing countries such as China and India, it caused the increase of the savings and prosperity (Miao et al., 2017). When it comes to macroeconomic effects, the effects of oil prices on inflation, capital market, investments and some other macro variables can be mentioned. Rising oil prices may lead to negative current balances, especially for oil importer countries, while contributing to the recovery from low inflation rates as an indicator of a strengthening world economy (Holmes \& Otero, 2017). In another study, Ewing and Thompson (2007) have investigated the relationship between macroeconomic variables such as consumer prices and industrial production. They have found that oil prices leading consumer prices but lagging industrial production (Miao et al., 2017). The study approaching from the other perspective has revealed that the effect of oil price to equity market performance in developed markets has varied throughout the sample. It leads to equity market in the beginning, however the reverse is happening in the end (Naccache, 2011). This situation is parallel to the findings already presented by Archanskala et al. (2012) who has expressed that oil price shocks were supply-driven in the past, but they have become demand-driven in the end of his sample. In brief, oil is an important input factor and it influences several investment decisions in almost all economic sectors. Therefore, not only short-term strategies, but also long-term decisions are based on information provided by this resource (Gronwald, 2012).

A very large part of the world's trade of this important source is made by seaborne, as mentioned earlier. One of the most prominent features of maritime transport is that it contains many different types of ships in different segments according to cargo type and volume. Therefore, the demand for each subsegment may show different fluctuations. Investing in a ship or hiring the ship for a specific load is affected by at least four factors; (i) the type of the commodity transported, (ii) the commodity parcel size (iii) the route and (iv) the loading/unloading port facilities (Alizadeh \& Nomikos, 2009). The types of ships designed and used in accordance with the oil transportation are tanker ships which moves oil from producer areas to consumer markets (Poulakidas \& Joutz, 2009). Tanker shipping in the international arena plays an important role in eliminating the imbalance between supply and demand in different regions. Besides, tanker shipping is a very important position in the international oil supply chain (Sun et al., 2014). However, demand for sea transport, as in all other sea transport modes, is determined by other factors and not by the state of the shipping market (Lyridis et al., 2017). In other words, demand for sea transportation is derived demand (Alizadeh \& Nomikos, 2004), and it is influenced by several factors, such as world economic conditions, international seaborne trade, seasonality, distance to transport goods (Alizadeh \& Nomikos, 2011) and the parcel size (Abouarghoub, 2011). When all these factors are converted into the factors affecting the demand for tanker transportation by Lyridis et al. (2017), the following factors has emerged; the growth of the world economy, oil shocks, war - hostile acts near oil production facilities, oil reserves, oil price, climate conditions, political decisions (e.g. OPEC policy) and new reserves.

The fact that demand for maritime transport is derived and directly influenced by demand side factors, some supply side developments forming the freight rates also directly affect the market. If there is a scarcity of supply capacity in the market, the balance between supply and demand for crude oil transportation becomes unbalanced which likely results in a higher freight rates. Because investing in a newbuilding ship or converting other types of vessels to tanker ships needs time (Shi et al., 2013). As the market conditions improve, these high incomes enable the whole fleet to be utilized. However, since the arrival of new vessels into the market takes time, the only way to increase supply in the short run can be achieved by increasing the productivity by increasing service speeds of the ships, and shortening port stays and ballast legs (Alizadeh \& Nomikos, 2011). In the long run the new vessels ordered enter the market and 
increase the supply side, causing the freight rates to go down again. This cycle is one of the most distinctive characteristics of the maritime market differentiating it from other markets.

It is seen that there are many factors affecting the tanker market up to this point. However, this study is motivated for making contributions to maritime literature by investigating the factors related to causality with tanker freight market and determining the most suitable one, and so filling a gap in the literature. Consequently, it has been determined that the relationship between the oil prices and the tanker market is often referred in the studies conducted. Therefore, it is useful to address the evaluations of this theoretical relationship to locate our study more firmly.

Glen and Martin (2005) explained the relationship with two possible scenarios. Firstly, when oil demand increases, the oil prices increase. This increase in demand also increases the demand for oil transportation which generates pickup in the transport market. Secondly, increase in oil price may be originated from reduction in oil supply. This situation decreases the demand for oil and consequently demand for oil transportation decreases, which causes fall in spot rates. Thereupon both of the scenarios can be justified and this makes relationship between oil price and freight rates complicated. Also, Shi et al. (2013) have expressed that since the demand for crude oil transport services is derived from the demand for oil, it is reasonable to say that oil price shocks are effective in the tanker freight market.

Empirical studies in the literature have reached similar conclusions about the relationship between oil price and tanker market. Miao et al. (2017) have used Baltic exchange dirty tanker index to analyze the freight rates for unrefined oil transportation on representative routes. As a result of their study, they have found a decline in freight rates when there is a decline in the oil price. In another study, Yongli and Yifei (2012) have analyzed causality between tanker freight rates and spot crude oil prices. They have found that there is a Granger causality from oil prices to freight rates. Poulakidas and Joutz (2009) have also used Granger causality analysis to study relationship between oil price and tanker rates. They have found the significant increase of freight rates, and the simultaneous increase in oil prices. Hummels (2007) have obtained results as maritime freight rates are highly sensitive to changes in oil prices. Alizadeh and Nomikos (2004) have examined the relationship in the US and they have found evidence for the existence of a longrun relationship between freight rates and oil prices. Also they have analyzed the relationship between freight rates and differential of WTI futures and physical crudes, however they haven't found evidence about this relation.

In the case of non-price-oriented studies, the results generally indicate that supply is also effective in the tanker market. The dynamics between freight rate and crude oil production level have been investigated in the paper studied by Lauenstein (2017). He has found that there is a causality from oil production to freight rates which is valid until the 2009 . The increase in excess transport capacity disrupts the causality after this point. Shi et al. (2013) has divided shocks into two on the tanker market as supply and non-supply shocks. The empirical results have provided evidence that crude oil supply shocks have significant effects on the tanker market. But the impact of non-supply shocks does not. In another study, Mayr and Tamvakis (1999) have observed that the increase in demand for imported crude oil increased the demand for sea transportation. This increase in demand have also lead increase on the level of freight rates. Shi et al. (2013) has examined the effect of the inventory levels on the tanker market, another aspect of the oil transport supply chain, and as a result, he has found that the increase in inventories has adversely affected the tanker market.

In this study we have examined the causality relationship between the tanker market and oil, and have decided that it would be more appropriate to use oil production variable rather than oil price. First of the main reasons for this is that the relationship with oil prices (Miao et al., 2017; Yongli \& Yifei, 2012; Poulakidas \& Joutz, 2009; Hummels, 2007; Alizadeh \& Nomikos, 2004) has been examined many times before. Secondly, fluctuations in oil prices are affected by political events (Lyridis et al., 2017) and can cause changes in price independently of the supply. Thirdly, one of the biggest costs of tankers is the cost of bunker and the increase in oil prices leads to an increase in this costs (Shi et al., 2013). This increase results in a compulsory rise in freight rates and a fake and misleading revival in the market. For all these reasons, it is 
more appropriate to examine the relationship between oil production and tanker market, and it is hoped that obtained results have provided better contribution to the maritime economics literature. Apart from this, it may be thought that when the demand for oil increases, oil production and oil prices may increase according to the law of supply and demand, which suggests that price and production variables might not be differentiated. In this regard, the results of the study done by Shi et al. (2013) can be suggested which have indicated that crude oil production has an insignificant impact on crude oil prices. He has also found that impact of crude oil price chock on the tanker market is limited. For all these reasons, the oil production variable has been selected and the causality relation between the tanker freight rates has been analyzed.

Bloomberg oil production index has been selected as a representative of production of crude oil, and Baltic Dirty Tanker Index (BDTI) and Baltic Clean Tanker Index (BCTI) have been selected as representatives of freight rates in the study. The Baltic Exchange in London daily publishes BDTI and BCTI to reflect the overall freight rate movements in the tanker market (Li et al., 2018), and these prices are quoted in a point of scale method known as Worldscale (Abouarghoub, 2011). Therefore, these indices can be regarded as strong representatives of freight rates in the tanker market. The relationship between variables in the study has been tested by linear causality analyze developed by Granger (1969) and nonlinear Granger causality analyze developed by Hiemstra and Jones (1996) and Diks and Panchenko (2006). Because linear causality analyzes may not capture the non-linear causal relations between the variables, and they may give the misleading result that there is no causality. At the end of the study, nonlinear causalities from production to freight rates have been found while the standard linear causalities have not been found. In addition, it has determined that the changes in oil production have an immediate effect on the clean tanker market but only after 1 period on the dirty tanker market. This may be due to product tankers being smaller or operating at shorter distances. Dirty tanker ships are much larger and operate at long distances, therefore the voyages and contracts are taking longer to complete.

Despite spikes due to shocks from supply and demand imbalances, freight rates are thought to be mean-reverting in the long-term. In the meantime, freight markets present great risks to its stakeholders because of huge capital requirements, challenging volatility levels, seasonality and sensitivity to energy prices and market sentiment (Abouarghoub, 2011). On top of that, the investment decisions of shipping companies are affected by freight rate behaviors (Li et al., 2018). Therefore, it is crucial to determine the impact of oil production on the tanker freight market in order to understand the movement of freight rates in the market. In this context, it is believed that the results of this study are a guide to shipowners and charterers in taking commercial decisions. It has also contributed to reducing the risks arising from the uncertainty in the tanker freight market.

The remainder of the paper is organized as follows; the method used is introduced in the second section; the results obtained are presented in the third section; and finally, the findings are discussed in the conclusion section.

\section{Methodology and Data}

The standard causality test was designed by Granger (1969) to determine the causal relationship between the two time series, and it examines whether the historical information of the first series could help improve the predictability of the present and future estimation for second time series (Yu et al., 2015). The idea behind Granger causality is quite simple. Let $X$ be an independent variable and $Y$ be a dependent variable. If $Y$ variable is better explained by $X$ variable and $X$ 's past values than its own past values, $X$ is expressed as Granger cause of $Y$ (Dura et al., 2017). The test spots a correlation between current value of first variable and the past values of second variable when the causality is the matter (Chiou-Wei, 2008). This test is standard causality test and analyzes causality with a linear approach.

Then as a result of the progress of studies in this area, Brock (1991) have developed a bivariate nonlinear model for demonstrating the way in which linear causality tests could fail to reveal nonlinear relations, which have uncovered that the linear causality tests are unsuccessful in determining the nonlinear relationships required by nature (Bal \& Rath 2015; Kumar, 2017; Adıgüzel et al., 2013). For instance, linear 
Granger causality tests have high power in spotting linear causal relations, however, when it comes to spotting nonlinear relations, their power may be low (Baek \& Brock, 1992; Hiemstra \& Jones, 1994; Balcilar et al., 2011).

Economic and financial series may follow nonlinear pattern due to high volatility, crises (Bildirici \& Turkmen, 2015), reform policies, sudden changes in economic structure and industrial production, and investor heterogeneity (Ajmi et al., 2013). Due to the all these reasons, it is inevitable that the relationship in every developed model is not linear.

The nonlinearity in the model should be tested first for the application of the nonlinear causality analysis. One of the most appropriate and common of these tests is the BDS Independence Test, designed by Brock, Dechert and Scheinkman (1987). It is applied to residuals of an estimated series of and checks whether the residuals are independent and identically distributed (i.i.d. assumption). The null hypothesis for this test indicates that the series is independent and identically distributed (Brock et al., 1996). Rejection of null hypothesis reveals that residuals contain some hidden, possibly non-linear structure. If the null hypothesis is rejected, the nonlinear Granger causality test would be more appropriate instead of linear one (Lim and Ho, 2013).

Various non-parametric methods are developed, in order to test for nonlinear Granger causality (Adıgüzel et al., 2013). The main ones of these tests are Baek and Brock (1992), Hiemstra and Jones (1994) and Diks and Panchenko (2006). A nonparametric statistical method for detecting non-linear Granger causality has been proposed by Baek and Brock (1992). It uses correlation integral between time series, but the series are assumed to be mutually and individually independent and identically distributed, which are thought to be strict assumption. Based on this, an improved test statistic for the non-linear causality which allows each series to display short-term temporal dependence has been developed by Hiemstra and Jones (1994). But as test-related studies progress further, it has been shown that $\mathrm{HJ}$ test can over-reject the null hypothesis of non-causality in the case of increasing sample size (Diks \& Panchenko, 2005). The new improved test statistic developed by Diks and Panchenko (2006) overcomes the rejection problem of HJ test.

The data set used in the study consists of 239 monthly observations covering between August 1998 and June 2018. While the Baltic Dirty Tanker Index (BDTI) and Baltic Clean Tanker Index (BCTI) variables are used as the measurement for the tanker freight rates, the Bloomberg oil production index variable is used as the production measurement. All variables were obtained from Bloomberg Data Platform. BDTI is a freight index calculated on the basis of the freight rates of the tanker vessels that transport crude oil on certain basic routes. BCTI is a similar index, but only difference is that it is calculated on the basis the tanker vessels that transport petroleum products. Therefore, vessels included in the BDTI are usually very large sized, while vessels included in the BCTI index are usually small sized. Bloomberg oil production index is a value calculated according to the amount of oil production all over the world.

A graphical representation of the variables used in this study is presented in the Graph 1 below. BDTI and $\mathrm{BCTI}$ represent freight rates on the tanker market and have followed a decreasing trend. The production variable is the Bloomberg production index and shows monthly total oil production in the world. Production has followed an increasing trend, contrary to freight rates in the period covered. The reasons for this situation may be caused by the following reasons; transport costs may have fallen due to the development of transportation technology; the increase in fleet may be more than the increase in demand, so there are more supply which makes freight rates fall down; there may have been a cost reduction due to oil prices. All these reasons are reasonable, but they are not in the scope of this study. 
Graph 1. BDTI, BCTI and Total Oil Production

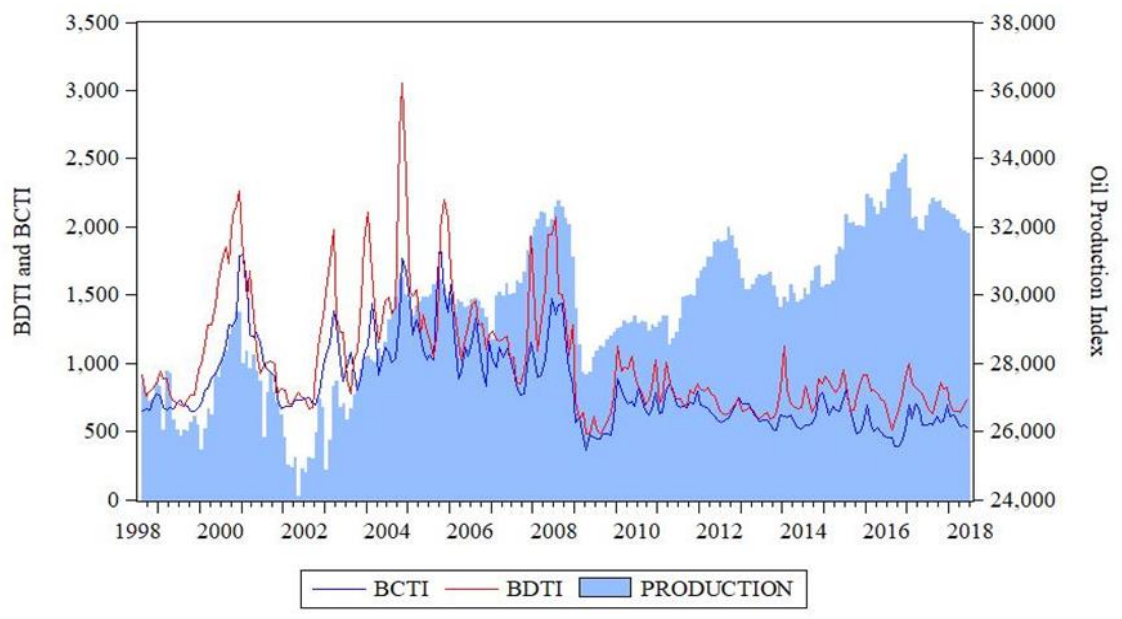

Source: Bloomberg Data Platform, 2018

The descriptive statistics of the variables used in the study are presented in Table 2. The production variable is already an index published on a monthly basis, while the BDTI and BCTI variables are converted to monthly data by taking the average of their daily values. The logarithms of the data are taken before the analysis starts, since this process makes the discrete data continuous and facilitates processing of the data.

Table 2. Descriptive Statistics of the Variables

\begin{tabular}{ccccccc}
\hline & BCTI & BDTI & Production & Ln BCTI & Ln BDT & Ln Prod. \\
\hline Mean & 831.0716 & 1024.889 & 29553.39 & 6.662573 & 6.858693 & 10.29120 \\
Median & 723.7143 & 857.0909 & 29820.00 & 6.584397 & 6.753544 & 10.30293 \\
Maximum & 1882.667 & 3050.000 & 34140.00 & 7.540444 & 8.022897 & 10.43822 \\
Minimum & 364.1500 & 477.8421 & 24100.00 & 5.897566 & 6.169280 & 10.08997 \\
Std. Dev. & 304.7175 & 434.3359 & 2177.912 & 0.341082 & 0.370100 & 0.074756 \\
Skewness & 1.103454 & 1.551898 & -0.242459 & 0.387781 & 0.680864 & -0.394673 \\
Kurtosis & 3.846396 & 5.636749 & 2.408664 & 2.522127 & 2.838686 & 2.527222 \\
Jarque-Bera & 55.63546 & 165.1688 & 5.823860 & 8.264005 & 18.72490 & 8.430591 \\
Probability & 0.000000 & 0.000000 & 0.054371 & 0.016051 & 0.000086 & 0.014768 \\
Observations & 239 & 239 & 239 & 239 & 239 & 239 \\
\hline
\end{tabular}

Source: Bloomberg Data Platform, 2018

In this study, standard Granger linear causality test is applied firstly. Then, the nonlinearity condition is examined and determined by the BDS test. Finally, a nonlinear Granger causality test is applied. In the following section, the results of the analysis are presented.

\section{Findings}

The series must be stationary in order to apply the linear and nonlinear Granger causality test. Therefore, augmented Dickey-Fuller (ADF) and Philips-Perron (PP) tests were applied and the results are presented in Table 3. The null hypothesis of this test is that the series are non-stationary and the results revealed that the BDTI and BCTI variables are stationary at level in both tests. However, the production variable is stationary at the level of $10 \%$ significance in Trend and Intercept according to the PP test. It is likely that there may be breaks in the series since the period covered includes economic booms and collapses. These breaks cause the level to change so that the series do not meet stationarity conditions. So unit root tests that take into account breaks in the level have also been applied to the series. 
Oil Production as a Leading Indicator for Tanker Freight Market

Table 3. Augmented Dickey Fuller and Philips-Perron Unit Root Test Results

\begin{tabular}{clcccc}
\hline & \multicolumn{1}{c}{ Level } & \multicolumn{2}{c}{ First Difference } \\
\hline \multicolumn{1}{c}{ Vest } & \multicolumn{1}{c}{ Variable } & Intercept & $\begin{array}{l}\text { Trend and } \\
\text { Intercept }\end{array}$ & Intercept & $\begin{array}{l}\text { Trend and } \\
\text { Intercept }\end{array}$ \\
\hline Augmented & Production & -1.747408 & -3.006552 & $-14.63468^{* * *}$ & $-14.60313^{* * *}$ \\
Dickey-Fuller & BDTI & $-3.969679^{* * *}$ & $-4.787633^{* * *}$ & $-13.27243^{* * *}$ & $-13.25009^{* * *}$ \\
& BCTI & $-2.697560^{*}$ & $-4.483991^{* * *}$ & $-12.47774^{* * *}$ & $-12.47174^{* * *}$ \\
Philips-Perron & Production & -1.807774 & $-3.260000^{*}$ & $-14.62023^{* * *}$ & $-14.58776^{* * *}$ \\
& BDTI & $-3.483382^{* * *}$ & $-4.130525^{* * *}$ & $-13.51126^{* * *}$ & $-13.49802^{* * *}$ \\
& BCTI & $-3.072317^{* *}$ & $-3.829972^{* *}$ & $-13.21520^{* * *}$ & $-13.19855^{* * *}$ \\
\hline
\end{tabular}

Critical values: $-2.57^{*}$ for $10 \%,-2.87^{* *}$ for $5 \%,-3.45^{* * *}$ for $1 \%$ at Intercept; $-3.13^{*}$ for $10 \%,-3.42^{* *}$ for $5 \%,-3.99^{* * *}$ for $1 \%$ at Trend and Intercept.

Unit root tests that consider breaks in level are applied to the series and results are presented in Table 4. These tests are one break ADF test (Zivot \& Andrews, 1992), one break LM test (Lee \& Strazicich, 2013), two breaks ADF test (Narayan \& Popp, 2010) and two breaks LM test (Lee \& Strazicich, 2003). These tests can detect one or two fractures in the series, and the null hypothesis of these tests indicates nonstationarity. According to the results of the one break ADF test, there are breaks in the all variables; October 2008 in the production variable, November 2008 in the BDI variable, August 2008 in BCTI variable. However non-stationary for the only Production variable cannot be rejected. The results of the one break LM test revealed that each variable has a break date; December 2000 in production variable; December 2008 in both $\mathrm{BDTI}$ and $\mathrm{BCTI}$ variables. Non-stationarity for production variable is rejected at $10 \%$ level this time. Two breaks ADF test indicates that non-stationarity for all the variables rejected at $1 \%$ level. Breaks in the production variable are August 2003 and October 2008; those in the BDTI are September 2003 and November 2008; and lastly those in the BCTI are September 2008 and August 2008. The last test for unit root including break in level is two breaks LM test and the results of the test showed that non-stationarity for production is rejected at $5 \%$ level while it is rejected for others at \%1 level. Break dates are December 2000 and May 2002 for production; October 2002 and December 2008 for BDTI; and November 2000 and July 2006 for BCTI. According to the general conclusions, breaks were generally realized in the big global economic crisis of 2008 and considering all these breaks, it can be said that all the variables are stationary.

Table 4. Unit Root Tests Including Break in Level

\begin{tabular}{llccc}
\hline & & Production & BDTI & BCTI \\
\hline One break & ADF-stat & -4.543 & $-6.215^{* * *}$ & $-5.127^{* *}$ \\
ADF test & Break date & $2008 \mathrm{M} 10$ & $2008 \mathrm{M} 11$ & $2008 \mathrm{M} 8$ \\
& Fraction & 0.515 & 0.519 & 0.506 \\
& Lag & 8.000 & 1.000 & 2.000 \\
\hline One break & LM-stat & $-3.388^{*}$ & $-5.664^{* * *}$ & $-3.768^{* *}$ \\
LM test & Break date & $2000 \mathrm{M} 12$ & $2008 \mathrm{M} 12$ & $2008 \mathrm{M} 12$ \\
& Fraction & 0.121 & 0.523 & 0.523 \\
& Lag & 9.000 & 1.000 & 2.000 \\
\hline Two & ADF-stat & $-5.298^{* * *}$ & $-7.171^{* * *}$ & $-7.075^{* * *}$ \\
breaks & Break dates & $2003 \mathrm{M} 8,2008 \mathrm{M} 10$ & $2003 \mathrm{M} 9,2008 \mathrm{M} 11$ & $2003 \mathrm{M} 9,2008 \mathrm{M} 8$ \\
ADF test & Fractions & $0.255,0.515$ & $0.259,0.519$ & $0.259,0.506$ \\
& Lag & 8.000 & 1.000 & 2.000 \\
\hline Two & LM-stat & $-3.889^{* *}$ & $-5.922^{* * *}$ & $-4.97^{* * *}$ \\
breaks LM & Break dates & $2000 \mathrm{M} 12,2002 \mathrm{M} 5$ & $2002 \mathrm{M} 10,2008 \mathrm{M} 12$ & $2000 \mathrm{M} 11,2006 \mathrm{M} 7$ \\
test & Fraction & $0.121,0.192$ & $0.213,0.523$ & $0.117,0.410$ \\
& Lag & 9.000 & 1.000 & 2.000 \\
\hline Critical Values: & $-4.58^{*}$ for $10 \%,-4.80^{* *}$ for $5 \%,-5.34^{* * *}$ for $1 \%$ at one break ADF test; $-3.21^{*}$ for $10 \%,-3.56^{* *}$ for $5 \%,-4.23^{* * *}$ for $1 \%$ at one \\
break LM test; $-3.98^{*}$ for 10\%, $-4.31^{* *}$ for $5 \%,-4.95^{* * *}$ for 1\% at two breaks ADF test; $3.50^{*}$ for $10 \%,-3.84^{* *}$ for $5 \%,-4.54^{* * *}$ for $1 \%$ at two \\
breaks LM test. & & & &
\end{tabular}


The traditional Granger causality test is conducted and the results are presented in Table 5 . The Schwarz information criterion (SC) is used in the analyzes, and the optimum lag is determined as 1. Probabilities are also calculated based on 1000 bootstrap replications. Obtained probability values showed that the null hypothesis that there is no causality cannot be rejected. On the other hand, when the Akaike information criterion (AIC) is used in the analyzes, a significant causality can be obtained. The AIC gives the optimum lag length of 12 , but this does not coincide with market conditions, since the observations are on a monthly basis. Therefore, the results are interpreted according to SC and it is concluded that there is no linear causality between the variables. Later on, BDS independence test is applied to the residuals of the VAR model.

Table 5. Result of the Standard Granger Causality Test

\begin{tabular}{lcc}
\hline & Production => BDTI & Production => BCTI \\
\hline Wald Stat & 1.190 & 1.163 \\
Asymptotic p-value & 0.275 & 0.281 \\
Bootstrap p-value & 0.271 & 0.273 \\
Optimal Lags & 1.000 & 1.000 \\
\hline
\end{tabular}

Default values are used for BDS analysis which is 0.7 for fraction of pairs and 6 for maximum dimensions. As mentioned in the method section, rejection of null hypothesis reveals that residuals contain some hidden, possibly non-linear structure. The null hypothesis is rejected in both models for all dimensions according to the results presented in Table 6, and it is found that the use of the non-linear Granger causality test is more appropriate. Later on, nonlinear causality analyzes are introduced.

Table 6. BDS Independence Test Results

\begin{tabular}{ccc}
\hline Dim. & BDTI Prob. & BCTI Prob. \\
\hline 2 & 0.0000 & 0.0042 \\
3 & 0.0000 & 0.0001 \\
4 & 0.0000 & 0.0000 \\
5 & 0.0000 & 0.0000 \\
6 & 0.0000 & 0.0000 \\
\hline
\end{tabular}

Table 7. Results of the Analysis

\begin{tabular}{|c|c|c|c|c|}
\hline \multicolumn{5}{|c|}{ Ln Production does not granger cause Ln BDTI } \\
\hline$|X=| Y=1$ & p_HJ=0.293795 & T_HJ=0.542333 & p_T2=0.133216 & T_T2=1.111318 \\
\hline$I X=\mid Y=2$ & p_HJ $=0.116646$ & T_HJ=1.191921 & p_T2 $=0.073811^{*}$ & T_T2=1.447985 \\
\hline$|X=| Y=3$ & p_HJ $=0.017760$ & T_HJ=2.102372 & p_T2 $=0.010461^{* *}$ & T_T2=2.309377 \\
\hline$I X=\mid Y=4$ & p_HJ $=0.046547$ & T_HJ=1.679299 & p_T2 $=0.028203^{* *}$ & T_T2=1.907891 \\
\hline \multicolumn{5}{|c|}{ Ln Production does not granger cause Ln BCTI } \\
\hline $\mathrm{IX}=\mid \mathrm{Y}=1$ & p_HJ $=0.143152$ & T_HJ=1.066264 & $p_{-} T 2=0.060265^{* *}$ & T_T2=1.552549 \\
\hline$|X=| Y=2$ & p_HJ $=0.107178$ & T_HJ=1.241678 & p_T2 $=0.069894^{* *}$ & T_T2=1.476584 \\
\hline$|X=| Y=3$ & p_HJ $=0.072809$ & T_HJ=1.455188 & p_T2 $=0.058950^{* *}$ & $T_{-} T 2=1.563653$ \\
\hline$|X=| Y=4$ & p_HJ $=0.030655$ & T_HJ=1.871249 & p_T2 $=0.034825^{* *}$ & $\mathrm{~T}_{-} \mathrm{T} 2=1.814178$ \\
\hline
\end{tabular}

Nonlinear Granger causality tests are applied and results are presented in Table 7. The values under the heading T_HJ are the causality values suggested by Hiemstra and Jones (1994). However, due to some shortcomings in these values, these values have been reassessed and standardized by Diks and Panchenko (2006). These new values are presented in the title T_T2. The values $p$ in the beginning indicate the probability values of the relevant statistics. According to the results, causalities from oil production to freight rates have been spotted from the second lag, which means change in production is felt in dirty tanker market 
with delay. The reflection on the dirty tanker market can be said to be over a month since the dataset used in the study is on a monthly basis. When the results of the clean tanker market are examined, it is determined that there are causalities from oil production to clean tanker market in all four delays.

\section{Conclusions and Discussions}

Since tanker freight rates are also affected by oil prices, the demand for tanker vessels in relation to price cannot be unambiguously revealed. This situation does not constitute an environment in which the parties can turn to advantage in chartering strategies. In addition, oil prices are unpredictable because they are influenced by unpredictable events such as political decisions and wars (Poulakadis \& Joutz, 2009; Shi et al., 2013; Naccache, 2011). The unpredictability of these events also makes it difficult to develop a strategy for the tanker sector stakeholders in advance. Oil production is also affected by similar incidents, but the impact on the tanker market is delayed when the vessels are considered for their time of voyage and the contracts. The effect of oil prices on the tanker market has been studied many times before (Miao et al., 2017; Yongli \& Yifei, 2012; Poulakidas \& Joutz, 2009; Hummels, 2007; Alizadeh \& Nomikos, 2004) and its existence cannot be denied, however the effect of oil production is thought to be more beneficial in taking commercial positions in the market. So the effect of oil production on the tanker freight market is examined in this study. Previously, this relationship has been examined by some researchers (Launstein, 2017; Shi et al., 2013; Mayr et al., 1999), but there have been no study investigating possible lagged nonlinear causal relationship between variables with DP (Diks \& Panchenko, 2006) test. Since the economic and financial series may follow nonlinear pattern due to high volatility, crises (Bildirici \& Turkmen, 2015), reform policies, sudden changes in economic structure and industrial production, and investor heterogeneity (Ajmi et al., 2013), it is inevitable that the relationship in our model may not be linear. Because the oil market contains all the things mentioned before. As a result of the linear causality test, no causality has been found, but nonlinearities have been determined in the developed VAR models by the BDS tests. Nonlinear causalities have been found in the both dirty and clean tanker markets with DP test applied in this regard. While the effects of production on the dirty tanker market are felt after 1 month (since the data is monthly), these effects are instantly felt in the product tanker market. These results eliminate some of the missing aspects of oil price-oriented studies by addressing the oil production as a key factor for tanker freight markets, and also, considering the non-linear relations, the results reveal the relationship in a way that is appropriate to the structure of the oil markets.

The results of the study show that there is no immediate causality from the changes in oil production to the dirty tanker market (BDTI), but there is an immediate causality to the product tanker market (BCTI). This may be due to product tankers being smaller or operating at shorter distances. Dirty tanker ships are much larger and operate at long distances, therefore the voyages and contracts are taking longer to complete. Crude oil is transported in very large quantities at very far distances. Because it is a standard product and is used in processing centers to be refined according to the needs of the customer. So customers of crude oil are countries or very large refined enterprises. According to the needs of small enterprises, crude oil purchase and processing is very difficult due to economies of scale and monopolistic market conditions. Large-scale customers can purchase very large quantities and reduce product and transportation costs per unit to unbeatable levels. On the other hand, product tankers serve relatively smaller customers with smaller cargo quantities. This is because purchasing large amounts of processed petroleum products at one time is both risky due to high and fluctuating prices, and the share of transportation costs in total product cost remains low. It is also quite expensive to build and purchase such ships, as product transportation requires extra equipment and robust design in the vessels. Briefly, crude oil is transported in large quantities to certain centers by large vessels, and processed products are distributed from this center in small quantities by small vessels. In this case, large ships carrying crude oil take a very long time to complete their voyages, while the ships carrying the product take very short time to complete their voyages. Therefore, the process of oil production to affect the crude oil market takes a little more time than the other market. According to these results, the transporting and contracting parties in both markets may try to maximize their interests and minimize their risks by following the oil production in the world. It is relatively more practicable to take action and act proactively in the dirty tanker market since the interaction in the crude oil market is delayed. 
Although the oil production values are very simple and accessible data, there are no studies investigating the relationship between these data and the tanker freight market. Probably they have not found to be worthy of research since no significant relationship could be found between them by linear models. The possibility that the relationship between variables is non-linear and delayed is ignored. However, this study provides a new perspective to researchers by making a significant contribution to the literature by revealing this significant relationship. It is hoped that these results may have risk-reducing benefits in the tanker market, which is capital intensity and have extreme volatility. In addition, it is directly affected by world economic situation and political decisions. These results may be beneficial to developing business strategies for shipowners and charterers in the tanker market.

Further studies may investigate why the impact on the dirty tanker market is lagged, but impact to the clean tanker market instantly in a clear way. The effects of production on the tanker market may also be examined on the basis of a certain tanker route or a certain the country of production.

\section{References}

Abouarghoub, W. (2011). Measuring shipping tanker freight risk (No. 02/10). Centre for Global Finance Working Paper. Adıgüzel, U., Bayat, T., Kayhan, S., \& Nazlıoğlu, Ş. (2013). Oil prices and exchange rates in Brazil, India and Turkey: Time and frequency domain causality analysis. Siyaset, Ekonomi ve Yönetim Araştırmaları Dergisi, 1(1), 49-73.

Ajmi, A. N., El Montasser, G., \& Nguyen, D. K. (2013). Testing the relationships between energy consumption and income in $\mathrm{G} 7$ countries with nonlinear causality tests. Economic Modelling, 35, 126-133.

Alizadeh, A. H., \& Nomikos, N. K. (2004). Cost of carry, causality and arbitrage between oil futures and tanker freight markets. Transportation Research Part E: Logistics and Transportation Review, 40(4), 297-316.

Alizadeh, A. H., \& Nomikos, N. K. (2011). Dynamics of the term structure and volatility of shipping freight rates. Journal of Transport Economics and Policy (JTEP), 45(1), 105-128.

Alizadeh, A., \& Nomikos, N. (2009). Shipping derivatives and risk management. Springer.

Angelier, J. P. (1991). The determinants of oil prices. Energy Studies Review, 3(3), 217-226.

Archanskaïa, E., Creel, J., \& Hubert, P. (2012). The nature of oil shocks and the global economy. Energy Policy, 42, 509520.

Baek, E., \& Brock, W. (1992). A general test for nonlinear Granger causality: Bivariate model. Working Paper. lowa State University and University of Wisconsin-Madison.

Bal, D. P., \& Rath, B. N. (2015). Nonlinear causality between crude oil price and exchange rate: A comparative study of China and India. Energy Economics, 51, 149-156.

Balcilar, M., Ozdemir, Z. A., \& Cakan, E. (2011). On the nonlinear causality between inflation and inflation uncertainty in the G3 countries. Journal of Applied Economics, 14(2), 269-296.

Bildirici, M. E., \& Turkmen, C. (2015). Nonlinear causality between oil and precious metals. Resources Policy, 46, 202211.

Bloomberg Data Platform (2018). Oil production index, Baltic dirty tanker index, Baltic clean tanker index. Retrieved August 10, 2018.

Brock, W. (1991). Causality, chaos, explanation and prediction in economics and finance. In: Casti, J., Karlqvist, A. (Eds.), Beyond belief: Randomness, prediction and explanation in science. CRC Press, Boca Raton, Fla.

Brock, W., Davis, D., Jose, S., \& Blake, L. (1996). A test for independence based on the correlation dimension. Econometric Reviews, 15(3), 197-235.

Brock, W., Dechect, W., \& Scheinkman, J. (1987). A test for independence based on the correlation dimension. Working Paper. Department of Economics, University of Wisconsin, Madison.

Chiou-Wei, S. Z., Chen, C. F., \& Zhu, Z. (2008). Economic growth and energy consumption revisited-Evidence from linear and nonlinear Granger causality. Energy Economics, 30(6), 3063-3076.

Diks, C., \& Panchenko, V. (2006). A new statistic and practical guidelines for nonparametric Granger causality testing. Journal of Economic Dynamics and Control, 30(9-10), 1647-1669. 
Dura, Y. C., Beser, M. K., \& Acaroglu, H. (2017). Econometric analysis of Turkey's export-led growth. Ege Akademik Bakis, 17(2), 295.

Ewing, B. T., \& Thompson, M. A. (2007). Dynamic cyclical comovements of oil prices with industrial production, consumer prices, unemployment, and stock prices. Energy Policy 35, 5535-5540.

Glen, D. R., \& Martin, B. T. (2005). A survey of the modelling of dry bulk and tanker markets. Research in Transportation Economics, 12(1), 19-64.

Granger, C. W. (1969). Investigating causal relations by econometric models and cross-spectral methods. Econometrica: Journal of the Econometric Society, 424-438.

Gronwald, M. (2012). A characterization of oil price behavior-Evidence from jump models. Energy Economics, 34(5), 1310-1317.

Hamilton, J. D. (2009). Understanding crude oil prices. The Energy Journal, 30(2), 179-206.

Hiemstra, C., \& Jones, J. D. (1994). Testing for linear and nonlinear Granger causality in the stock price-volume relation. The Journal of Finance, 49(5), 1639-1664.

Holmes, M. J., \& Otero, J. (2017). Re-examining the movements of crude oil spot and futures prices over time. Energy Economics, $x(x), x x-x x$.

Hummels, D. (2007). Transportation costs and international trade in the second era of globalization. Journal of Economic Perspectives, 21(3), 131-154.

Kilian, L., Rebucci, A., \& Spatafora, N. (2009). Oil shocks and external balances. Journal of international Economics, 77(2), 181-194.

Kumar, S. (2017). On the nonlinear relation between crude oil and gold. Resources Policy, 51, 219-224.

Lauenstein, P. (2017). The dynamic relationship between tanker freight rates and crude oil production: Evidence from causality analysis. International Journal of Trade and Global Markets, 10(4), 267-289.

Lee, J., \& Strazicich, M. C. (2003). Minimum Lagrange multiplier unit root test with two structural breaks. Review of Economics and Statistics, 85(4), 1082-1089.

Lee, J., \& Strazicich, M. C. (2013). Minimum LM unit root test with one structural breaks. Economics Bulletin, 33(4), 2483-2492.

Li, T., Xue, L., Chen, Y., Chen, F., Miao, Y., Shao, X., \& Zhang, C. (2018). Insights from multifractality analysis of tanker freight market volatility with common external factor of crude oil price. Physica A: Statistical Mechanics and its Applications, 505, 374-384.

Lim, S. Y., \& Ho, C. M. (2013). Nonlinearity in ASEAN-5 export-led growth model: Empirical evidence from nonparametric approach. Economic Modelling, 32, 136-145.

Lyridis, D., Manos, N., Zacharioudakis, P., Pappas, A., \& Mavris, A. (2017). Measuring tanker market future risk with the use of FORESIM. Journal of Economics and Business, 67(1), 38-53.

Mayr, T., \& Tamvakis, M. (1999). The dynamic relationship between paper petroleum refining and physical trade of crude oil into the United States. Maritime Policy \& Management, 26, 127-136.

Miao, H., Ramchander, S., Wang, T., \& Yang, D. (2017). Influential factors in crude oil price forecasting. Energy Economics, 68, 77-88.

Naccache, T. (2011). Oil price cycles and wavelets. Energy Economics, 33(2), 338-352.

Narayan, P. K., \& Popp, S. (2010). A new unit root test with two structural breaks in level and slope at unknown time. Journal of Applied Statistics, 37(9), 1425-1438.

Poulakidas, A., \& Joutz, F. (2009). Exploring the link between oil prices and tanker rates. Maritime Policy \& Management, 36(3), 215-233.

Shi, W., Yang, Z., \& Li, K. X. (2013) The impact of crude oil price on the tanker market. Maritime Policy \& Management, 40(4), 309-322.

Sun, X., Tang, L., Yang, Y., Wu, D., \& Li, J. (2014). Identifying the dynamic relationship between tanker freight rates and oil prices: In the perspective of multiscale relevance. Economic Modelling, 42, 287-295.

Tokic, D. (2015). The 2014 oil bust: Causes and consequences. Energy Policy, 85, 162-169.

UNCTAD (2018). Review of Maritime Transport 2017.

Wirl, F. (2008). Why do oil prices jump (or fall)? Energy Policy, 36, 1029-1043 
Yongli, Y., \& Yifei, Z. (2012). Correlation between Tanker freight and the price of spot crude oil-based on Granger causality analysis. Journal of Chongqing Jiaotong University (Natural Science), 5, 0-42.

Yu, L., Li, J., Tang, L., \& Wang, S. (2015). Linear and nonlinear Granger causality investigation between carbon market and crude oil market: A multi-scale approach. Energy Economics, 51, 300-311.

Zivot, E., \& Andrews, D. (1992). Further evidence of the great crash, the oil-price shock and the unit-root hypothesis. Journal of Business and Economic Statistics, 10, 251-70. 
This Page Intentionally Left Blank 